\title{
A Review of Hydroflorocarbons (HFC'S) Refrigerants as an Alternative to R134a Refrigerant
}

\author{
Shridhar Vasant Raskar ${ }^{+*}$ and Sachin Vyasrao Mutalikdesai ${ }^{\dagger}$ \\ ${ }^{\dagger}$ Mechanical Engineering Department, Trinity College of Engineering and Research, Pune, Maharashtra, India \\ Accepted 01 Sept 2016, Available online 02 Sept 2016, Vol.6, No.5 (Oct 2016)
}

\begin{abstract}
The 80\% Indians domestic refrigerators use R134a as refrigerant due to its excellent thermodynamic and thermo physical properties. However, because of higher GWP (1300) its impact on environment is dangerous. Due to such hazardous impact, it is necessary to find out an alternative refrigerant for R134a without affecting performance of vapor compression system. This paper investigate performance of vapor compression refrigeration system with alternative eco-friendly refrigerants such as R32, R134a, R152a, R290, R1270, R600a, RE170, R290.Vapor compression system work on four processes compression, evaporation, expansion and condensation. During analysis, various parameters like evaporating pressure, pressure ratio, and power per ton of refrigeration, volumetric cooling capacity, compression work and coefficient of performance are considered. R152a and RE170 are better alternative refrigerants to R134a. These refrigerants shows $4.65 \%$ and $6.27 \%$ more COP than that of conventional R134a refrigerant respectively.
\end{abstract}

Keywords: Refrigerants, ozone depletion potential, global warming potential, coefficient of performance

\section{Introduction}

A Chlorofluorocarbon (CFC) refrigerants are used in different application as medical instruments as a dry cleaning sterilants, refrigeration and air conditioning system as a refrigerant, chemical/pharmaceutical industry, automotive industry and above all in the food industry all over world. In 1987, the Montreal protocol phase-out the use and production of CFCs in developed and developing country since January 1996 and 2010 (Bolaji B.0.). The performances of hydro fluorocarbon (HFC) refrigerants R12, R152a and R134a investigated experimentally. It is found that R152a shows the best desirable environmental requirements; having zero ozone depletion potential (ODP) and very low global warming potential (GWP).Whereas R32 shows undesirable characteristics such as high operating temperature and pressure, low volumetric cooling capacity (VCC) and low coefficient of performance (COP). The vapor pressures of R152a and R134a are nearly the same, but vapor pressure of R32 is higher than that of $\mathrm{R} 134 \mathrm{a}$ by $37.2 \%$. The performance of $\mathrm{R} 152 \mathrm{a}$ refrigerant is approximately similar to R134a refrigerant. Therefore, R152a is considered as a good alternative for R134a (Bolaji B.0. et al). Analysis of energy and energy for R134a, R152a, R290, R600 and $\mathrm{R} 600 \mathrm{a}$ refrigerants had done with parameters such as coefficient of performance, energy efficiency, energy

*Corresponding author: Shridhar Vasant Raskar destruction ratio and efficiency defect. It shows that R152a has the highest value of coefficient of performance and highest value of energetic efficiency among R134a, R152a, R290, and R600a refrigerants. Work efficiency defect is maximum in condenser and lowest in evaporator (Gaurav).

The $80 \%$ Indians domestic refrigerators use R134a as refrigerant due to its excellent thermodynamic and thermo physical properties. But because of its higher GWP of 1300 it impact on environment is dangerous. R600a, R290 and blends of R290 and R600a are the better option for the replacement of R134a in domestic refrigerator, due to their low global worming potential (GWP) and zero ozone depletion potential (ODP) (Khansaheb Safvan). Experimental investigation on vapor compression refrigeration system with aluminum micro channel condenser using R134a and $\mathrm{R} 152 \mathrm{a}$ is performed. It is shows that refrigerant charge of R152a was reduced by $40 \%$ over R134a (Bhatkar V. W. et $a$ l). For mobile air-conditioners combination of Hfo1234yf and R32 is proposed as alternative refrigerant to conventional R134a because of low GWP. The results indicates that heat transfer coefficients of blending were 10-20\% greater than pure Hfo1234yf under conditions of large mass and heat fluxes (Minxia Li et $a l$ ). The performance of vapor compression refrigeration system is affected by properties of refrigerant used in the system. Table 1 shows some important properties of refrigerant. 
Table 1: Some properties and environmental impact of selected alternative refrigerants

\begin{tabular}{|c|c|c|c|c|c|}
\hline Refrigerants & $\begin{array}{c}\text { Chemical } \\
\text { Formula }\end{array}$ & $\begin{array}{c}\text { Latent Heat } \\
\text { of } \\
\text { Evaporation } \\
\text { (Kj/Kg) }\end{array}$ & ODP & GWP & $\begin{array}{c}\text { Safety } \\
\text { Class }\end{array}$ \\
\hline R32 & CH2F2 & 360.24 & 0 & 650 & A3 \\
\hline R134a & CH2FCF3 & 215.9 & 0 & 1300 & A1 \\
\hline R152a & CHF2CH3 & 301 & 0 & 140 & A2L \\
\hline R290 & C3H8 & 425.59 & 0 & 3 & A3 \\
\hline R600a & C4H10 & 386 & 0 & 3 & A3 \\
\hline
\end{tabular}

\section{Theoretical Construction and Working Principle of Vapor Compression Refrigeration System}

Vapor compression refrigeration system is works on the second law of thermodynamics given by Rudolf Clausius. "It is impossible for a self acting system working in a cyclic process without any external force, to transfer heat from a body at a lower temperature to a body at a higher temperature. It considers transformation of heat between two heat reservoirs. " The construction of vapor compression refrigeration system is shown in Figure 1. Major component of vapor compression system are compressor, expansion valve, condenser and evaporator.

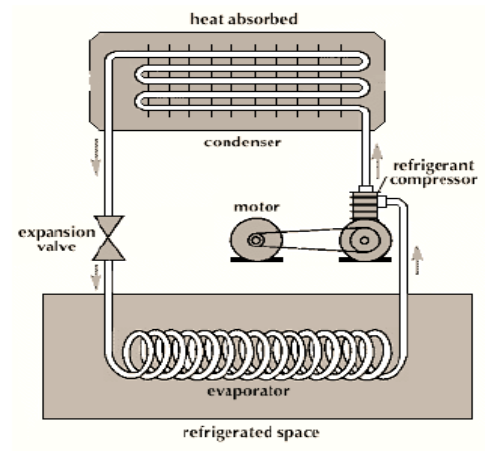

Figure 1 Vapor compression refrigeration system (Verma Jitendra Kumar)

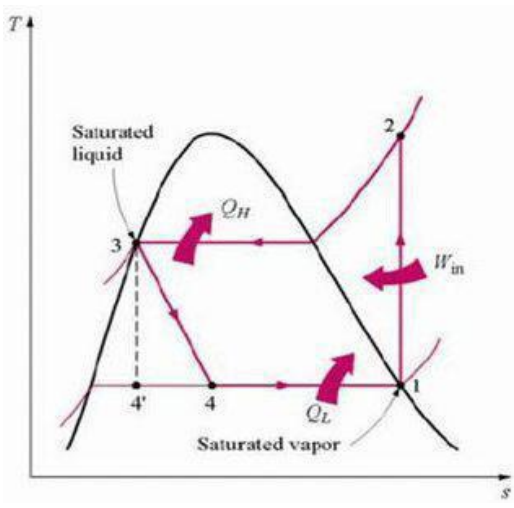

Figure 2 T-S diagram for the ideal vapor compression refrigeration system (Chavan S. P and Mahajan S. D)

The T-S and P-h diagrams for ideal vapor compression refrigeration system are as shown in Figure 2 and Figure 3. Process 4-1 indicates evaporation during which liquid refrigerant absorbed latent heat from space is to cool. Process 1-2 indicates compression, which increases pressure and temperature of vapor refrigerant simultaneously above the surroundings. In process 2-3 vapor refrigerant condensed by rejecting latent heat to surrounding. The expansion process is shown by 3-4, where pressure and temperature of liquid refrigerant decreases simultaneously.

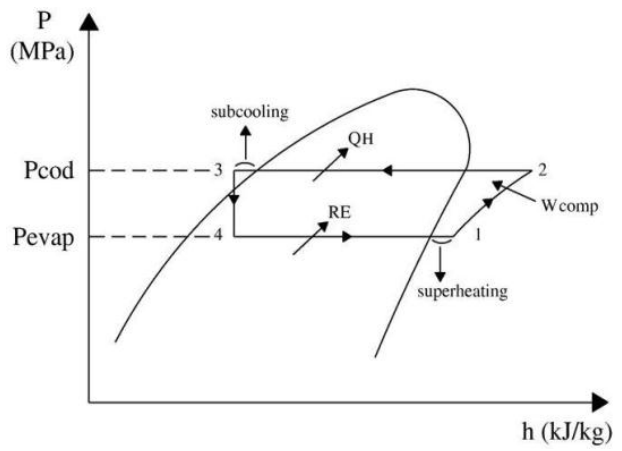

Figure 3 P-h diagram for compression refrigeration system (Chavan S. P and Mahajan S. D)

\section{Results and Discussions}

\section{Evaporating Pressure Vs Evaporating Temperature}

Weight of equipment parts and accessories depend upon evaporator vapor pressure. As evaporator vapor pressure increases weight of equipment also increases.

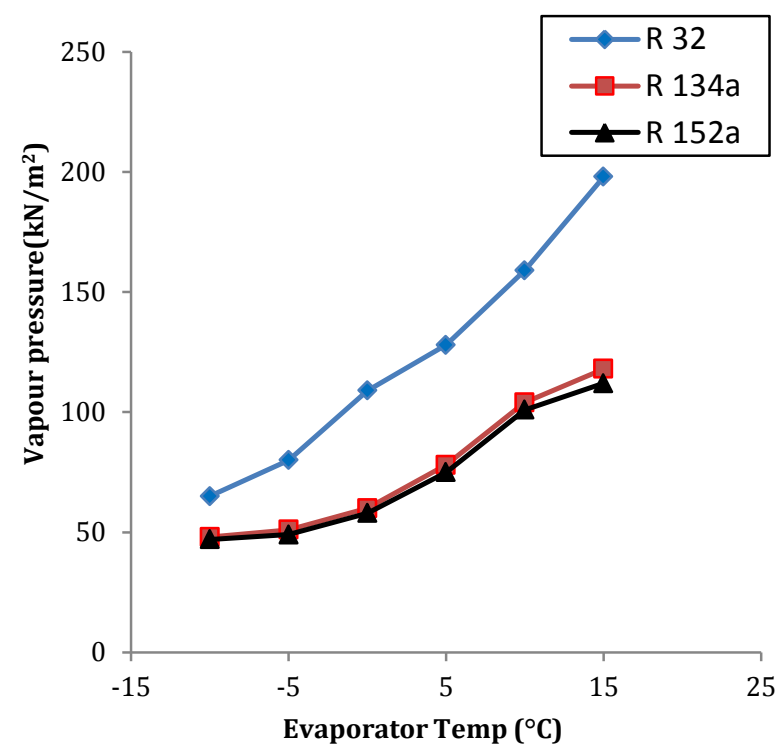

Figure 4 Vapor pressure Vs Evaporator temperature for R32, R152a and R134a (Bolaji B.O. et al)

An evaporator vapor pressure of R152a, RE170 and $\mathrm{R} 600 \mathrm{a}$ is lower than that of R134a as shown in Figure 4 and 5. Whereas evaporator vapors pressure of R32, $\mathrm{R} 1270, \mathrm{R} 290$ is higher than R134a at various evaporating temperature. R600a shows minimum vapor pressure, while R32 shows maximum vapor pressure for different evaporator temperature. 


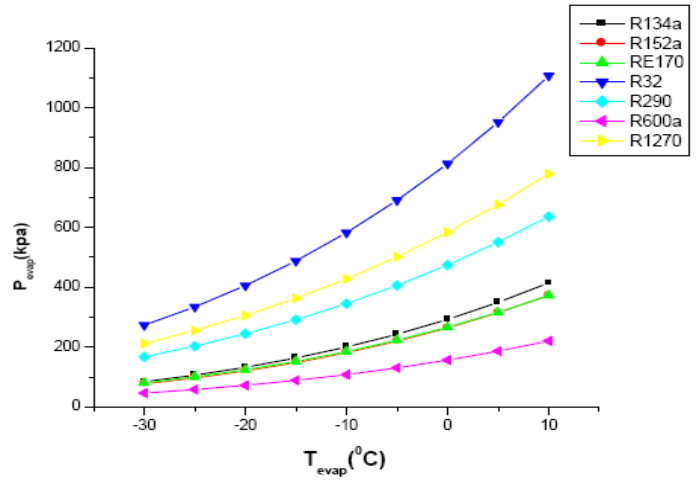

Figure 5 Evaporating pressure Vs evaporating temperature (Baskaran. A et al)

\section{Pressure Ratio Vs Evaporating Temperature}

Figure 6 and 7 shows an inverse relation between a pressure ratio and evaporating temperature. A pressure ratio of $152 \mathrm{a}$ is $1.2 \%$ lower than $\mathrm{R} 134 \mathrm{a}$ as shown in Figure 6. While, Figure 7 indicates that pressure ratio of $152 \mathrm{a}$ and RE170 is $2.6 \%$ and $5.94 \%$ lower than R134a.

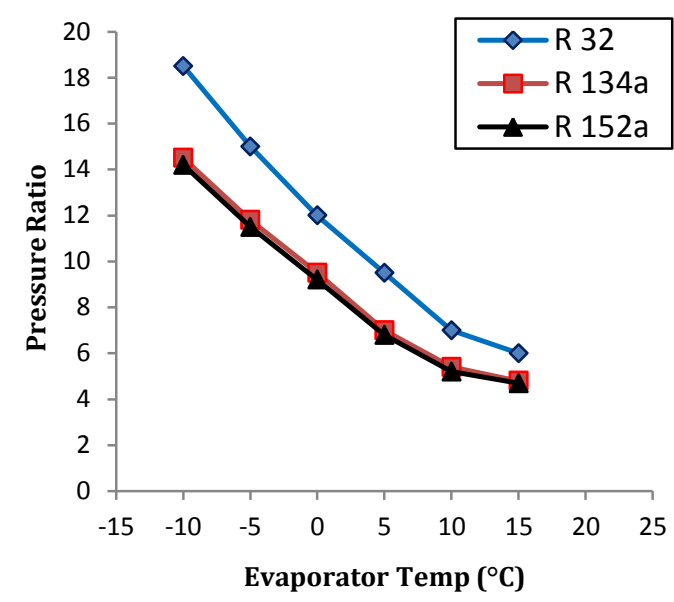

Figure 6 Pressure ratio Vs Evaporator temperature for R32, R152a and R134a (B.0. Bolaji et al)

Figure 7 also shows that pressure ratio R1270, R290 and R32 lower than R134a, while pressure ratio of $\mathrm{R} 600 \mathrm{a}$ is slightly higher than conventional R134a.

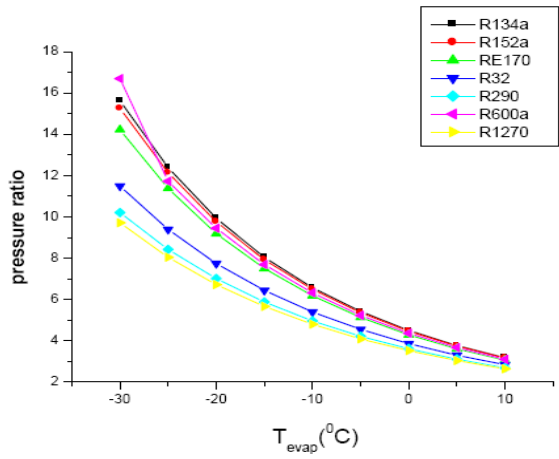

Figure 7 Pressure ratio Vs evaporating temperature (Baskaran. A et al)
Power per Ton of Refrigeration Vs Evaporating Temperature

Figure 8 shows that as evaporating temperature increases power per ton of refrigeration reduces. RE170, R600a, R152a, consumed less power per ton of refrigeration as compare with R134a. The power consumed by $\mathrm{R} 134 \mathrm{a}$ at $-10{ }^{\circ} \mathrm{C}$ evaporator temperature was $1.057 \mathrm{KW} / \mathrm{TR}$, while RE170, R600a, R152a consume $0.994 \mathrm{KW} / \mathrm{TR}, 1.023 \mathrm{KW} / \mathrm{TR}, 1.008 \mathrm{KW} / \mathrm{TR}$ power respectively.

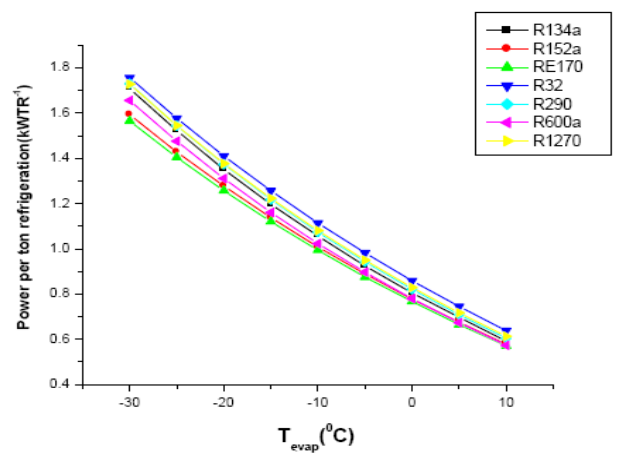

Figure 8 Power per ton of refrigeration Vs evaporating temperature (Baskaran. A et al)

For the same evaporator temperature, power consumed by R32, R290 and R1270 are 1.114 KW/TR $1.074 \mathrm{KW} / \mathrm{TR}$ and $1.081 \mathrm{KW} / \mathrm{TR}$ respectively. R32 consumes the more power per ton of refrigeration.

Volumetric Cooling Capacity Vs Evaporating Temperature

Figure 9 shows that volumetric cooling capacity (VCC) increases with increase in evaporating temperature. It is because of decrease in specific volume and more cooling effect.

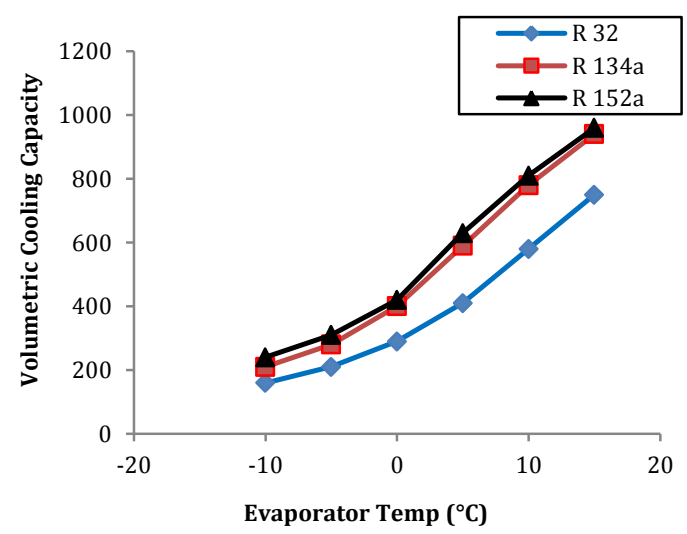

Figure 9 Volumetric cooling capacity (VCC) Vs Evaporator temperature for R32, R152a and R134a (B.O. Bolaji et $a l$ )

R152a shows nearly the same volumetric cooling capacity as that of R134a whereas R32 shows $25.2 \%$ lower volumetric cooling capacity than R134a. 


\section{Compression Work Vs Evaporating Temperature}

Figure 10 indicates that RE170, R152a and R600a consume less power compared to R134a. While R32, R1270 and R290 consume more power compared to R134a. RE170 consume minimum power, whereas R32 consume maximum power for different evaporating temperature.

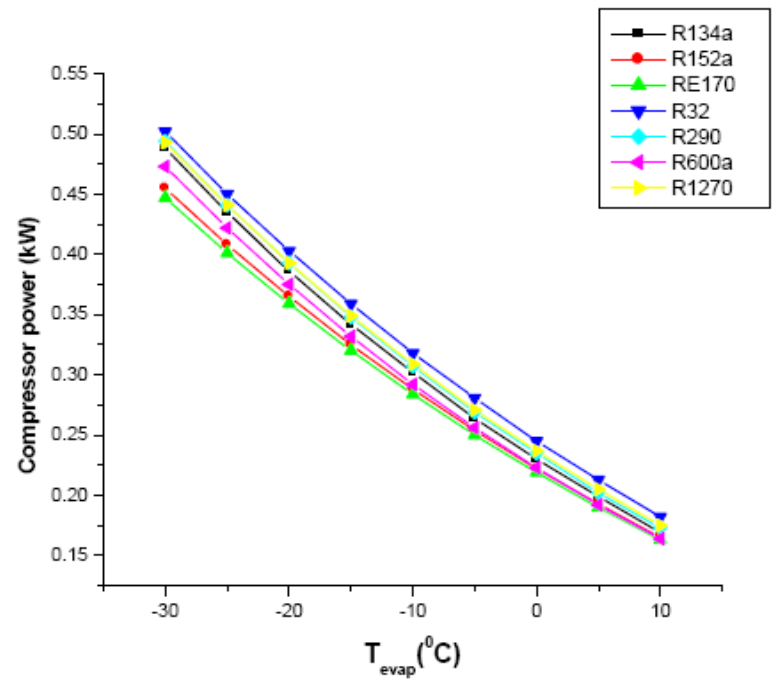

Figure 10 Compressor Power Vs evaporating temperature (Baskaran. A et al)

\section{Coefficient of Performance Vs Evaporating Temperature}

Figure 11 and 12 show that COP increases with increase in evaporative temperature. R152a has 4.65\% higher COP than R134a while R32 has 5.25\% lower COP than R134a as shown in Figure 11.

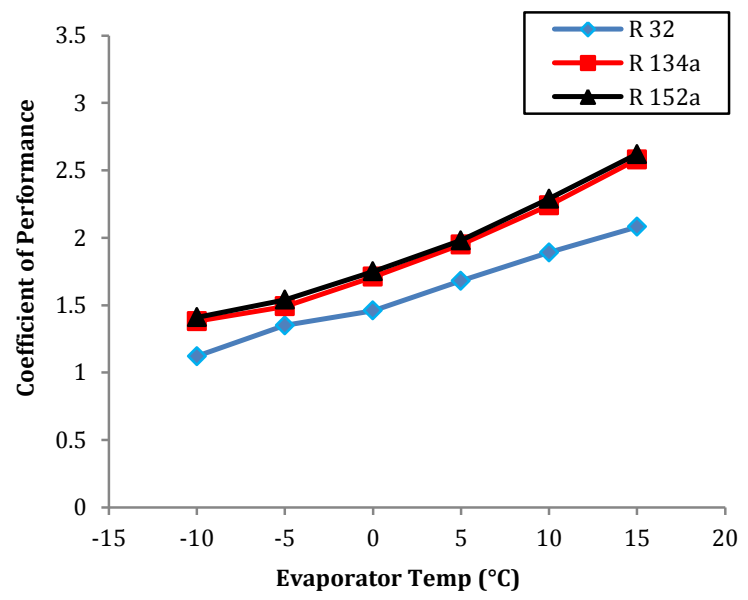

Figure 11 Coefficient of performance (COP) Vs Evaporator temperature for R32, R152a and R134a (B.0. Bolaji et al)

Figure 12 shows that COP of RE170 is higher than that of R134a, while COP of R290, R1270 are $1.72 \%, 2.32 \%$ lower than that of $\mathrm{R} 134 \mathrm{a}$ respectively.

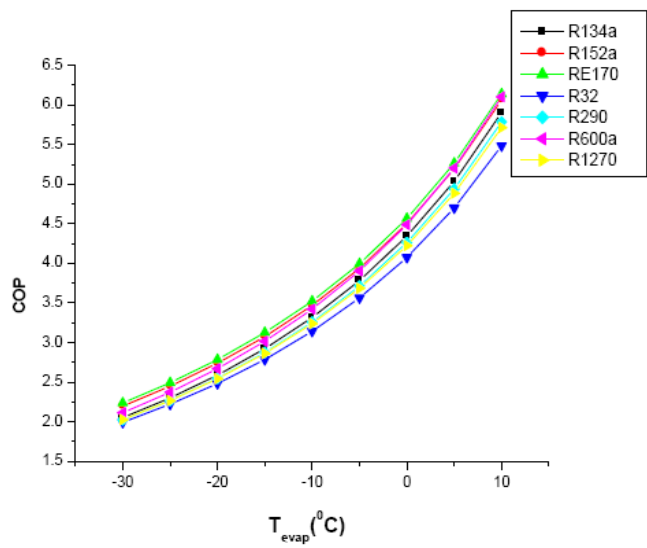

Figure 12 Coefficient performance Vs evaporation temperature (Baskaran. A et al)

\section{Conclusion}

In this paper performance vapor compression refrigeration system is investigated with various alternative refrigerants. The refrigerants considered during analysis are RE170, R152a, R32, R290, R600a and $\mathrm{R} 1270$.The results compared with conventional R134a refrigerant. During the analysis different parameters such as evaporating pressure, pressure ratio, power per ton of refrigeration, volumetric cooling capacity, compression work, coefficient of performance etc. are considered. From this investigation following conclusion are drawn:

1) R152a and RE170 offer the best desirable properties that are less harmful to environment. These refrigerants have zero Ozone Depletion Potential (ODP) and negligible Global Warming Potential (GWP). On other side R32, R1270 and R600a shows undesirable characteristics, such as high operating temperature and pressure, low coefficient of performance (COP) and low volumetric cooling capacity (VCC).

2) Evaporator vapor pressures of R32, R1270 and R290 are higher as compare with R134a. Whereas R152a, RE170 and R600a indicate, lower evaporator vapor pressure at various evaporating temperature than R134a.

3) Refrigerants 152a, RE170, R290, and R1270 shows lower pressure ratio than $\mathrm{R} 134 \mathrm{a}$.

4) The volumetric cooling capacity (VCC) of R32 is less than that of R134a by $25.2 \%$ whereas R152a shows nearly the same volumetric cooling capacity as R134a over the considered range of operating conditions.

5) COP of R152a, RE170, and R600a is more than R134a. While other side COP of R1270, R32 and R290 less than R134a.

\section{References}

Bolaji. B. O. (2011), Selection of environment-friendly refrigerants and the current alternatives in vapor compression refrigeration systems, Journal of Science and Management, Vol 1, No. 1 
Bolaji.B.0. Akintunde. M.A. Falade, (2011), Comparative analysis of performance of three ozone-friends HFC refrigerants in a vapor compression refrigerator, Journal of Sustainable Energy and Environment. 2, 61-64

Gaurav, Kumar Raj (2014), Performance Analysis of Household Refrigerator with Alternate Refrigerants, International Journal of Innovative Research in Science, Engineering and Technology, Vol. 3, Issue 4

Khansaheb Safvan, Kapadia R.G,(2015), A Review on Domestic Refrigerator Using Hydrocarbons as Alternative Refrigerants to R134a, International Journal of Innovative Research in Science, Engineering and Technology, Vol. 4 Special Issue 6

Bhatkar V. W., Kriplani V. M., Awari G. K.(2015),Experimental Performance Of R134a And R152a Using Micro channel Condenser Journal of Thermal Engineering Yildiz Technical University Press, Istanbul, Turkey vol.1, Special Issue 2, No. 7, pp. 575-582

Li. Minxia, Dang Chaobin, and EijiHihara,(2012) ,Flow boiling heat transfer of HF01234yf and R32 refrigerant mixtures in a smooth horizontal tube: Part I. Experimental investigation, International Journal of Heat and Mass Transfer 55, pp. 3437-3446,
Baskaran.A, Koshy.P Mathews,(2012),A Performance Comparison of Vapor Compression Refrigeration System Using Eco Friendly Refrigerants of Low Global Warming Potential, International Journal of Scientific and Research Publications, Volume 2, Issue 9

Verma Jitendra Kumar, Satsangi Ankit, Chaturani Vishal (2013),A Review of Alternative to R134a (CH3CH2F) Refrigerant, International Journal of Emerging Technology and Advanced Engineering, Volume 3, Issue 1

Chavhan Sandip P, Mahajan S. D (2013), A Review of an Alternative to R134a Refrigerant in Domestic Refrigerator, International Journal of Emerging Technology and Advanced Engineering , Volume 3, Issue 9

Cabello.R, Torrella.E, Navarro-Esbri.J, (2004), Experimental evaluation of a vapor compression plant performance using R134a, RR407C and R22 as working fluids, Applied Thermal Engineering 24,

Calm James M., (2002), Emissions and environmental impacts from air-conditioning and refrigeration systems, International Journal of Refrigeration 25, pp. 293-305. 